\title{
Editorial
}

\section{Introduction to the special issue on digital government and gender}

\author{
Mila Gasco-Hernandez ${ }^{\mathrm{a}}$, Giorgia Nesti ${ }^{\mathrm{b}}$, Maria Cucciniello ${ }^{\mathrm{c}}$ and Yenisel Gulatee ${ }^{\mathrm{d}}$ \\ ${ }^{a}$ Center for Technology in Government and Rockefeller College of Public Affairs and Policy, University \\ at Albany, State University of New York, Albany, NY, USA \\ ${ }^{\mathrm{b}}$ University of Padova, Padova, Italy \\ ${ }^{\mathrm{c}}$ University of Edinburgh Business School, Edinburgh, United Kingdom \\ ${ }^{\mathrm{d}}$ University at Albany, State University of New York, Albany, NY, USA
}

"I love technology, and I don't think it's something that should divide along gender lines" Marissa Meyer, novelist

\section{Neglected topic in the literature on digital government}

Information and communication technologies (ICTs) are not gender-neutral: they are not accessed, managed and controlled by all men and women equally. According to the International Telecommunications Union (2019), women are lagging behind men in making use of the Internet in almost two thirds of countries worldwide. Overall, the proportion of all women using the Internet globally is $48 \%$, compared with $58 \%$ of all men. More men than women use the Internet in every region of the world except in the Americas, where the gender gap continues to hover around 0 and in the European Union (EU), where the percentage of men using the Internet in 2020 was 89,4 compared with 88,1 of women. ${ }^{1}$ In Africa, the Arab States and Asia-Pacific, meanwhile, the digital gender gap is starting to grow.

While the literature on the digital divide has widely addressed this gender digital gap (e.g., Bimber, 2000; Cooper, 2006; Brännström, 2012; Cooper \& Weaver, 2013; Gray et al., 2017), interestingly enough, its potential implications for electronic government (e-government) research and practice have hardly been studied (for one exception: Choi \& Park, 2013). This is mainly due to the lack of conclusive data on gender divides in e-government provided by international organizations. For instance, the UN E-government survey generally claims that there is a small but persistent difference in online usage between men and women (UN Department of Economic and Social Affairs, 2018) while, according to the

\footnotetext{
${ }^{1}$ See https://digital-agenda-data.eu.
} 
European Institute for Gender Equality (EIGE), gender differences in the usage of the Internet in the EU to interact with public authorities in 2019 are not relevant. ${ }^{2}$

Yet, only a few studies highlight that most electronic e-government initiatives have been implemented without taking into account the potential gender-based differences in technology usage behavior (Sarabdeen \& Rodrigues, 2010; Rufin-Moreno et al., 2013), assuming that users of e-government are predominantly male (Solvak et al., 2019). Among other, studies have not sufficiently addressed how cumulative e-government adoption, peak adoption rate, and usage depth and duration may differ in age and gender taken together. They have neither considered how gender roles may affect e-government use or the influence of gender on determinants of e-government adoption.

Further, more than two decades of feminist studies in technology design suggest that the diversity of women's needs or preferences may be overlooked in favor of masculinist perspectives (Oudshoorn et al., 2004; Rommes et al., 2012). This lack of gender awareness is also present in the e-government literature and, as a result, there is not enough evidence on the benefits of e-government for women, which have mainly been addressed by a few reports from international organizations (e.g. UN Department of Economic and Social Affairs, 2020; Sample, 2018; Melhem et al., 2009). This is particularly relevant for women who experience multiple social disadvantages, exclusion, and marginalization (Martin \& Goggin, 2016) and it could become even worst due to the impact of the recent COVID-19 pandemic.

The exclusion of gender considerations from e-government research has also expanded to other areas of digital government. Only very recently, a few voices are starting to acknowledge the role of women in this field. That is the case, for example, of the Feminist Open Government Initiative in the framework of the Open Government Partnership, which promotes the ideas of equitable and equal access to transparency, participation and accountability from government, ensuring that governments are responsive to the diverse and gendered needs of all citizens, and that implementation of such initiatives is gender sensitive (Open Government Partnership, 2019). In the framework of open government, open data projects have also been useful to shed light on important topics concerning women, such as health, gender-based violence, equality, and empowerment (e.g. Equal Measures 2030, 2018). Research on smart cities has also echoed this trend and has explored whether, where, how, and why gender discriminations could emerge in the context of a smart city (Nesti, 2019). The use of big data and its potential applications for women seems to also be affected by a gender data gap that keeps highlighting the lack of gender diversity in technology (Criado Perez, 2019; D'Ignazio \& Klein, 2020). And studies on Artificial Intelligence in the public sector have also expressed concern about the risk to develop gender-biased algorithms that may affect public service delivery (e.g., Agarwal, 2018; Busuioc, 2020; Leavy, 2018; Wirtz et al., 2019) but again, empirical research in this field is lacking.

\section{Contents of the special issue: Five articles, one comparative country report and two book reviews}

Given the scarce attention that the role of gender in digital government studies has received, which shows the need for further and consistent research, this Special Issue presents five articles, one comparative country report, and two book reviews, which characterize the current state of understanding and open an opportunity to build a research agenda on digital government and gender.

\footnotetext{
${ }^{2}$ The percentage of women aged 16-74 who used e-government services in 2019, in fact, was 52 while the percentage of men was 54 (EIGE Gender Statistics Database, available at https://eige.europa.eu/gender-statistics/dgs/indicator/ta_resdig_ dig_egov_isoc_bde15ei).
} 
First, in their conceptual article, "A critical analysis of the study of gender and technology in government", Mary Feeney and Federica Fusi acknowledge that feminist research has been rarely applied to the analysis of the use, adoption, and implementation of technology in government settings from the perspective of public managers and employees. The authors then explore feminist theoretical approaches in technology and organizational studies and identify and describe three gender research streams: 1) gender as a social construct, 2) gender bias in data, technology use, and design, and 3) gendered representation. For each stream, they propose a set of research questions and empirical propositions for advancing research on e-government and gender in public sector workplaces.

The second article, "Gendering the digital divide: The use of electronic government services and implications for the digital gender gap", Javiera F. M. Macaya, Manuella Maia Ribeiro, Tatiana Jereissati, Camila dos Reis Lima, and Maria Alexandra Cunha study the digital divide in Brazil and how it affects the use of e-government services. Drawing on the analysis of the ICT Household 2019 survey data, the authors show that in Brazil there is a significant gender gap in e-government usage. They conclude that gender is an important determinant of unequal access to these services. Further, the authors explore how this "gendered" digital divide may affect adoption and use of online public services and acknowledge the need for public managers to design more effective e-government solutions that take into account gender-related differences in the adoption and use of e-government.

The topic of (continuous) use is also the focus of the third article titled "Gender difference in the continuance intention to e-file income tax returns in Pakistan". In it, Saman Arshad and Sobia Khurram investigate if there is a significant difference in the continuance usage intention of income tax e-filing between men and women in Pakistan and conclude that there is indeed a gender gap. Even if such service is used at least once by women, they are still reluctant to continue its usage in the future.

Articles four and five present empirical research focused on other components of digital government. The first one, "The gendered digital turn: Canadian mayors on social media", by Katherine V.R. Sullivan, studies the use of social media by Canadian mayors. The author concludes that, despite the fact that women occupy lesser positions of power at all political levels in Canada, they are more active on social media: in comparison with men mayors, a higher proportion of women mayors have a Facebook page, as well as Twitter and Instagram accounts and actively use them outside of electoral campaigns. These results highlight the importance of segmenting political roles when studying the feminization rate, especially when some roles are in subordination to others.

The last article, titled "Feminist perspectives to artificial intelligence. Comparing the policy frames of the European Union and Spain" and authored by Ariana Guevara-Gomez, Lucia Ortiz de Zarate-Alcarazo, and J. Ignacio Criado, analyze European and Spanish official documents about artificial intelligence (AI) to understand how they approach gender issues. The authors conclude that although the AI frameworks of both Spain and the European Union are gender-sensitive, they are not exempt of challenges mainly related to the definition of gender used in the documents and the practical implementation practices.

This Special Issue also includes a comparative country report that examines the development of digital governance in Mongolia and Taiwan. Its authors, Battulga Buyannemekh and Tzuhao Chen, study the use of information and communication technologies (ICT) by women and men in the two countries across four facets: 1) infrastructure, 2) digital literacy and skills, 3) usage patterns, and 4) e-government services and civic participation. Although they acknowledge the existence of gender inequalities in digital opportunities, which requires governmental attention and intervention in both countries, Mongolia seems to have a deeper digital gender gap.

Finally, the Special Issue closes with two book reviews conducted by Elisabeth Dubois (African Women, ICT and Neoliberal Politics, by Assata Zerai, Routledge Focus, 2019) and Marta Arniani (Data Feminism, by Catherine D'Ignazio and Lauren Klein, MIT Press, 2020). 


\section{Developing a research agenda}

Collectively, the articles included in this Special Issue indicate that researchers worldwide are building a consistent research agenda around the topic of digital government and gender. They suggest that there is a long way ahead and that further research should be conducted in order to better understand how inequalities interact and impact women's willingness and propensity to adopt and use digital government as well as how digital government impacts women's quality of life. Additionally, a gender perspective should be integrated in designing public services in order to better assess women's needs and to avoid gender biases especially in emerging fields such as AI and big data analysis.

In particular, future quantitative and qualitative studies could help grow the research agenda on digital government and gender by investigating the interaction of gender with other variables such as race, age, education, and socioeconomic situation in the use of online public services by women. These studies would provide a comprehensive understanding of use and they would also help public managers and decision makers to better design online public services, more targeted to their users. Studies could also focus on better understanding the impact of the use of technology and of digital government specifically, by gender. Such studies would shed light on the differences (and the causes of these differences) between men and women, but also on the impact technology may have on the LGBTQ community, a largely ignored topic in the current literature. Future research could also focus on the gender-based use of different technologies and participation in technology-based initiatives, further exploring the variation in drivers, determinants, and outcomes among social media, online participation platforms, digital co-production, and online services, to just name a few examples. Finally, other themes on the research agenda could address the role of gender in the design and implementation of digital government programs, not only in terms of taking gender needs into account but, also, in relation to leadership roles, as well as data-based analyses of the impact of AI on gender inequality.

\section{Acknowledgments}

We would like to thank the authors for their efforts, their insights, and their contributions to further developing this important domain. In addition, the feedback and insightful comments provided by reviewers have proved very valuable to improve the manuscripts and we also want to thank them for their generosity. Finally, we also want to thank everyone involved in making this Special Issue possible at Information Polity and, in particular, Gabriela Ricci, for effectively managing the production process, Albert Meijer and William Webster, the co-editors in chief, for their input as the Special Issue was taking shape, and Karl Lofgren, for managing the books review process.

\section{References}

Agarwal, P.K. (2018). Public administration challenges in the world of AI and bots. Public Administration Review, 78(6), 917-921.

Bimber, B. (2000). Measuring the gender gap on the Internet. Social Science Quarterly, 81(3), 868-876.

Brännström, I. (2012). Gender and digital divide 2000-2008 in two low-income economies in Sub-Saharan Africa: Kenya and Somalia in official statistics. Government Information Quality, 29(1), 60-67.

Busuioc, M. (2020). Accountable Artificial Intelligence: Holding algorithms to account. Public Administration Review, 1-12.

Cooper, J. (2006). The digital divide: The special case of gender. Journal of Computer Assisted Learning, 22(5), 320-334.

Criado Perez, C. (2019). Invisible Women: Exposing data bias in a world designed for men. New York: Abrams Press. 
Choi, Y-T., \& Park, S. (2013). Understanding gender inequality in central e-government: A Korean case study. Government Information Quarterly, 30(3), 300-309.

D’Ignazio, K., \& Klein, L. (2020). Data Feminism. Cambridge: The MIT Press.

Equal Measures 2030 (2018). Data driving change: Introducing the EM2030 SDG Gender Index. Surrey: Equal Measures 2030.

Joel, J., \& Weaver, K. D. (2013). Gender and computers: Understanding the digital divide. New York: Routledge.

Gray, T. J., Gainous, J., \& Wagner, K. (2017). Gender and the digital divide in Latin America. Social Science Quarterly, 98(1), 326-340.

International Telecommunications Union (2019). Measuring digital development Facts and figures 2019. Geneva: International Telecommunications Union.

Leavy, S. (2018). Gender bias in Artificial Intelligence: The need for diversity and gender theory in machine learning. Paper presented at the $40^{\text {th }}$ International Conference on Software Engineering. Gothenburg, Sweden, May-June.

Martin, F., \& Goggin, G. (2016). Digital transformation? Gendering the end user in digital government policy. Journal of Information Policy, 6, 436-459.

Melhem, S., Morrell, C., \& Tandon, N. (2009). Information and communication technologies for women's socioeconomic empowerment. Washington DC: The World Bank.

Nesti, G. (2019). Mainstreaming gender equality in smart cities: Theoretical, methodological and empirical challenges. Information Polity, 24(3), 289-304.

Open Government Partnership (2019). Feminist open government: Addressing gender equity challenges in open government co-creation processes. Case studies from Latin America, Africa and Asia. Document available at https://www. opengovpartnership.org/wp-content/uploads/2019/05/fogo-main-report_web.pdf.

Oudshoorn, N., Rommes, E., \& Stienstra, M. (2004). Configuring the user as everybody: Gender and design cultures in information and communication technologies. Science, Technology, and Human Values, 29(1), 30-63.

Rommes, E., Bath, C., Maas, S. (2012). Methodology for intervention: Gender analysis and feminist design of ICT. Science, Technology, and Human Values, 37(6), 653-662.

Rufin Moreno, R., Medina Molina, C., Sánchez Figueroa, J. C. \& Rey Moreno, M. (2013). Gender and e-government adoption in Spain. International Journal of Electronic Government Research, 9(3), 23-42.

Sample, K. (2018). Gender mainstreaming in the transparency fund. Washington DC: Inter-American Development Bank.

Sarabdeen, J., \& Rodrigues, G. (2010). Gender differences in e-government adoption in Dubai. The Business Review, 16(2), $120-126$.

Solvak, M., Unt, T., Rozgonjuk, D., Vork, A., Veskimae, M., \& Vassil, K. (2019). E-governance diffusion: Population level e-service adoption rates and usage patterns. Telematics and Informatics, 36), 39-54.

UN Department of Economic and Social Affairs (2018). United Nations e-government survey 2018. Gearing E-Government to support transformation towards sustainable and resilient societies. New York: United Nations.

UN Department of Economic and Social Affairs (2020). United Nations e-government survey 2020. Digital government in the decade of action for sustainable development. New York: United Nations.

Wirtz, B.W., Weyerer, J.C., \& Geyer, C. (2019) Artificial Intelligence and the public aector - Applications and challenges. International Journal of Public Administration, 42(7), 596-615. 